\title{
A Pragmatic Approach to the Composition, Types, Functions and Interpretations of Chinese-specific Curse Guo Ma "ta ma de" and Its Variants
}

\author{
Yantao Zeng ${ }^{1}$, Yuemei Liu ${ }^{2}$ \\ ${ }^{1}$ School of Foreign Studies, South China Normal University, Guangzhou, China \\ ${ }^{2}$ Department of Foreign Languages, Yangjiang Open University, Yangjiang, China
}

Email address:

ytzengchina@aliyun.com (Yantao Zeng)

\section{To cite this article:}

Yantao Zeng, Yuemei Liu. A Pragmatic Approach to the Composition, Types, Functions and Interpretations of Chinese-specific Curse Guo Ma "ta ma de" and Its Variants. International Journal of Language and Linguistics. Vol. 9, No. 4, 2021, pp. 188-195. doi: $10.11648 /$ j.ijl1.20210904.17

Received: June 14, 2021; Accepted: June 29, 2021; Published: July 10, 2021

\begin{abstract}
Guo Ma (Chinese-specific cursing terms) is a type of scolding expressions widely spread in colloquial Chinese, expressing such emotion as dislike, grudge, indignation. Searching the internet reveals that, while there are many comments and essays about this kind of words, a theoretically systematical discussion of their construction, pragmatic and textual function is rare. This paper, based on corpus observation and questionnaire analysis, aims at exploring the composition, types, functions and pragmatic forces of Chinese-specific cursing terms ta ma de and its variants. It is revealed that: (1) There are eight main types of Chinese-specific cursing words in ta ma de and its variants; (2) These cursing terms under observation convey not only negative attitude and emotion as traditionally recognized but also neutral or even positive attitude and emotion; (3) Chinese national curse ta ma de and its variants are phrases used not only to perform the pragmatic function of swearing but also play a grammatical cognitive function. The researchers do not intend to offer a deliberate justification for these terms but show that they are not diabolic expressions and deserve a full attention of linguists.
\end{abstract}

Keywords: Guo Ma (Chinese-specific Curse), Composition \& Type, Function \& Meaning

\section{Introduction}

Four score and ten years ago, Lu Xun, a well-known Chinese litterateur in 1930s, wrote an essay entitled On ta ma $d e !$, in which he did a detailed and humorous research into the origin, features and evolution of Chinese-specific cursing term ta $m a d e^{1}[6,7]$, and by analogy with the practice of calling peony China's national flower ${ }^{2}$, ta ma de is referred to as Guo $\mathrm{Ma}^{3}$, an orthodox academic name given by Lu Xun, which is a highly condensed generalization of this kind of cursing words $[13,17]$.

Since its birth, the Chinese-specific cursing term ta ma de

1 ta ma de (他妈的), a widespread Chinese cursing term which is roughly equal to "damn it, blast it, to hell with it, Gosh, or fuck" in English.

2 Lu Xun described in his sketch essay "On ta ma de (fuck)": "..... If, as people often said, peony is China's national flower, ta ma de can be regarded as China's national curse."

3 Guo Ma means national scolding (words). has had a super-strong vitality and a strong popular base. No other colloquial expression can surpass ta ma de in terms of the geographical extent of use, the degree of popularity, and the frequency of occurrence. From the highbrow to the lowbrow, people of all walks of life in China are all familiar with it. As Mr Lu Xun said," whoever lives in China must have heard ta ma de or similar mantra. I think that its distribution probably follows the footprints of Chinese people, the frequency of its use is perhaps no less than the polite greeting term nin hao (Hello)." [6, 7]

Among many variants of Guo Ma in Chinese, the most common one is ta ma de (similar to "fucking" in English) [3, 14]. Because of its vulgarity and indecency, although widely spread in spoken language, it is tabooed by lofty-minded literati in the written Chinese language, and thus ignored even in the dictionaries. By consulting such dictionaries as Modern Chinese Dictionary (1984), Chinese-English Dictionary (2001) and Modern Chinese-English Dictionary 
(1988), it can be found that neither the word ta ma de and its variants, nor the academic term Guo Ma enters these dictionaries, which shows how much offensive it is in Chinese. The attitude of Chinese people toward it is probably contradictory, they both hate and love it, otherwise it will not be so popular and have such a high frequency of appearance while getting so much ostracization and accusation. It is the secular, cultural and social significance imposed by the custom that makes the word so ferocious and heinous.

Searching the internet reveals that, while there are many comments and essays about this kind of words [2, 18], a theoretically systematical discussion of the law of their construction, structure, pragmatic and textual function is rare, a gap this paper intends to fill. The authors propose that language researchers should not ignore such widely used words because of their vulgarity.

\section{The construction and Types of Chinese-specific Cursing Term ta ma $d e$ and Its Variants}

The linguistic representations of Guo Ma (national scolding or curse) in Chinese are those abusive expressions used for swearing and catharsis. Due to the rich vocabulary, exquisite rhetoric and strong local characteristic of Chinese language, the forms of expressing Chinese-specific national scolding are also multifarious, colorful and of a wide variety $[4,14]$. The ancient words of cursing in the classic and historical books are yi fu (servants), nu (slaves), si gong (dead person), which are mild in insulting force, whereas lao gou(old dog), he $z i$ (racoon dog) are more powerful in insulting force, and much worse than these are the words which are related to the older generations such as er mu bei ye (your mother is maidservant), zhui yan yi chou (adopted by an eunuch and leave behind a disgrace [6]. In modern times, a lot of new varieties have appeared. For instance, a list below of cursing quotations on campus shows that these widely-spread cursing expressions are no less frequent than the normal daily greeting ni chi fan le ma (have you had a meal?).

1) 你个土鳖,伸个鳖头不睡觉,一看就不是个好鳖。(said by a teacher during a nap check in a middle school)

-ni ge tu bie, shen ge bie tou bu shui jiao, yi kan jiu bu shi ge hao bie.

-You turtle, stretch a turtle head do not sleep, a look is not a good turtle.

-You hillbilly, peak with heading but not sleep, it is clear that you are indocile.

2) 我操! 你们开会呢? (said by a teacher during a night check after lights out)

-wo cao! ni men kai hui ni?

-I fuck! You have a meeting?

-Fuck! Are you having a meeting?

3) 你妈个屄的,不愿意在这里睡就给我滚回家去。有娘 养,没娘教的畜生。(students reprimanded by a teacher because they laugh and talk in the dormitory after lights out)

-ni ma ge bi de, bu yuan yi zai zhe li shui jiu gei wo gun hui jia qu. you niang yang, mei niang jiao de chu sheng.

-Your mother's vaginal orifice, not want to sleep here go home. There is a mother, no mother teach of animals.

-Fuck your mum, if you don't want to sleep here, go home. You are like a creature, born of a mother but not taught by her.

4) ***, 操你妈! 交作业!(urge to hand in homework after morning reading)

-xxx, cao ni ma! jiao zuo ye!

-xxx, Fuck you mum! Hand in homework!

-xxx, Fuck! Hand in your homework!

5) A: ***, 操你妈的请我吃饭。

$\mathrm{B}$ : 凭什么, 我他妈的还没钱呢。(同学之间平时交流)

-A: xxx, cao ni ma de qing wo chi fan.

-B: ping shen me, wo ta ma de hai mei qian ni.

-A: $x x x$, fuck you mum invite me to have rice.

-B: by what, I fuck you mum no money.

-A: xxx, fuck, you should invite me to a dinner.

-B: why, I'm fucking poor.

6) 我靠! 他妈的又迟到了。

-wo kao! ta ma de you chi dao le.

-I fuck! His mother's again late.

-Fuck! damn it, I'm late again.

7) 哎呀。他妈的气死我了。谁他妈的课下在我这儿坐

着了。(Scolding when student occupancy occurs)

-ai ya. ta ma de qi si wo le. shui ta ma de ke xia zai wo zhe er zuo zhe le.

-Oops. His mother's make me so upset. Who his mother's class over in my here sitting.

-Oops. Fucking pissed me off. Who the hell is sitting here in my chair after class.

8) 你他妈的真漂亮, 我他妈的看上你了。咱俩他娘的谈 恋爱吧。

-Ni ta ma de zhen piao liang, wo ta ma de kan shang ni le. za liang ta niang de tan lian ai ba.

-You his mother's too beautiful, I his mother settle on you. We two his mother's talk love.

-You're fucking beautiful. I fucking like you. Let's fucking have a relationship.

A short essay by Li Ming Jiang Nan lists eight categories of abusive words in Chinese. Although the essay discusses and classifies the national abuse in a playful tone, but it is good enough to illustrate the wide variety and mulriple types of national abuse. It can also be seen from the corpus collected by the author that the linguistc embodiment of national scolding can take many forms. Due to the space limitation, this paper does not intend to study all the forms of national abuse, but focuses only on the most common forms and types of national abuse. Data shows $X+m a$ de and its derivative structures are the most common national scolding. Based on the corpus of the author, this kind of national scolding can be summed up into eight main structures:

(1) Pronoun + the appellation of relatives + auxiliary $d e$, 
such as ni ma de, ta ma de, ni lao lao de, ta nai nai de, ni nai nai de, ni niang de, sometimes the specific body parts of the person addressed are added to this structure, such as ni ma ge bi de (your mother's vaginal orifice). This kind of structure is strictly restricted in the choice of personal pronouns, usually the second and third person singular is preferred.

Which personal pronoun to choose depends on the object of scolding. In general, if the object of scolding is a direct object of the discourse (hearer), the second person is chosen, as in (9). If the object of scolding is not the direct object of the discourse, the third person is chosen, as in (10). Of course, influenced by such factors as avoidance, euphemism, politeness, face as required by the communicative context, the speaker may scold the locust while pointing at the mulberry, so that even if the object of scolding is the direct object of the discourse, the third person may be chosen, as in (11).

9) 你妈的,没长眼睛吗,前面有人还冲过来。

-ni ma de, mei zhang yan jing ma, qian mian you ren hai chong guo lai.

-Your mother's, not have eyes? In front there's someone still rush forward.

-Damn it, don't you have eyes? You still rush forward even when there is someone in front of you.

10)他妈的, 我还真没见过这样难缠的说客。

-ta ma de, wo hai zhen mei jian guo zhe yang nan chan de shui ke.

-His mother's, I not really see such tough lobbyist.

-Blast it, I've never seen such a tough lobbyist.

11)烸,这也算是爱情的伟大力量吧, 真他妈的一喂,你有 没有注意到, 我现在“他妈的' 也骂得少了? 跟你们这 种人混,连三字经也不能骂,真憋气。

-hai, zhe ye suan shi ai qing de wei da li liang ba, zhen ta ma de - wei, ni you mei you zhu yi dao, wo xian zai "ta ma de"ye ma de shao le? gen ni men zhe zhong ren hun, lian san zi jing ye bu neng ma, zhen bie qi.

-Hey, this is love's great power, really his mother's hey, you yes or no notice, I now "his mother's" curse little? With a guy like you hang, even the three-word can't scold, really suffocating.

-Hey, that's the great power of love, isn't it? Fuck Hey, have you noticed that I seldom say "fucking" now? To stay together with you, I can't even say these three characters for scolding, which really suffocates me.

(2) the appellation of relatives + auxiliary de, such as $m a$ de, lao lao de, nai nai de, niang de. This structure can be regarded as the simplification of the first structure above, the difference is that the structure has no object in reference, the tone tends to be mild, and the pragmatic effect tends to be neutral.

(3) Pronoun + Pronoun $t a+$ the appellation of relatives + auxiliary (de), such as wo ta ma (de), ni ta ma (de), wo ta nai nai de. Compared with the first structure, this structure has one more pronoun, and the second pronoun remains unchanged, which means that this structure is more definite in reference. Compare the following sentences:

12)你妈的(他妈的), 这么大的事你都不给我说一声。 -ni ma de (ta ma de), zhe me da de shi ni dou bu gei wo shuo yi sheng.

-Your mother's (his mother's), such important thing you not tell me.

-Fuck, you won't tell me anything so important.

13)你他妈的,我怎么就没有想到这上面去呢。

-ni ta ma de, wo zen me jiu mei you xiang dao zhe shang mian qu ni.

-You his mother's, I how not think of going up here.

-Fuck you, how come I didn't think of this.

14)我他妈的,你要我这样说让我怎么做人。

-wo ta ma de, ni yao wo zhe yang shuo rang wo zen me zuo ren.

-I your mother's, you want me say so let me how be man.

-Fuck me, you ask me to say that, then how can I behave myself?

15)我他妈的, 前世造莩攀上你他妈的这门亲。

-Wo ta ma de, qian shi zao nie pan shang ni ta ma de zhe men qin.

-I your mother's, in my last life did evil and become you mother's related to you by marriage.

-Fuck me, I must have done evil in my last life, otherwise we'd not have become fucking related to your family by marriage.

In sentence 12, no matter which person is used in the curse, it will not affect the object the second part of the sentence points at. Sentences 13-15, however, are different, sentence 13 implies a contrast between "I" and "you", meaning "you thought of it whereas I didn't", so sentence 13 can be changed by adding to the curse words as ni ta ma de (zhen chong ming) (you fucking (really smart)), but can not be replaced by wo ta ma de (zhen chong ming) (I fucking (really smart)). In sentences 14 and 15 , there is no contrastive meaning, yet the appearance of the first pronoun in the abuse wo ta ma de highlights its subject referential meaning, especially when it appears in the position of exterior modifiers. Sentence 14 highlights "I", implying an emphasis on "how the hell can I behave myself". If sentence 14 changed to "fuck you...", "you" is highlighted, implying an emphasis on blame on "you". Sentence 15 highlights "I" by saying wo ta ma de (fuck me), emphasizing "my helplessness". If the abuse is changed as ni ta ma de(fuck you), then "I" is hidden whereas "you" is highlighted, implying an emphasis on complaints of or dissatisfaction with "you". It can be seen that if the first pronoun in this structure is different, the focus at which the information of the whole sentence aims will be different.

(4) Pronoun + pronoun $t a+$ the appellation of relatives, such as "ni ta ma (you fucking), what's wrong with me ?"," wo ta ma (I fucking), you are a rare person!". This kind of structure is actually the simplification of the third structure, and the second pronoun in structure (3) and (4) is fixed as "ta (he)" and can not be replaced by other pronouns, while the first pronoun can be the first person or the second person singular or plural. For example

16)你们他妈,就不可以少说点,看把人家给气的。 -Ni men ta ma, jiu bu ky yi shao shuo dian, kan ba ren 
jia gei qi de.

-You his mother, not may little say? Look make other angry.

-Fuck you, why don't you shut up a little bit? Look, how angry was she made?

(5) Pronoun + the appellation of relatives. This structure is rare, usually used in a limited number of cases. The choice of pronouns in it is highly limited. In most cases, this structure plays the role of a national scolding only when the second person singular as in ni lao lao (your grandmother) is used in it and the whole structure appears as a one-member sentence. Sometimes this structure with the third person singular pronoun in it (as in ta lao lao (his grandmother)) may also have the same function, but it is rare. If other pronouns are used in this structure, such as za lao lao(our grandmother), wo men lao lao(our grandmother), ta men lao lao(their grandmother), wo lao lao(my grandmother), the function of national scolding is lost.

(6) Verb + pronoun + the appellation of relatives + de. Examples are qu ta ma de (fuck his mum), qu ta nai nai de (fuck his granny), qu ni lao lao de (fuck your granny-in-law), cao ta nai nai de (fuck his granny), diao ta niang de (fuck his mum), diao ta ma de (fuck his mum), diao ni ma de (fuck your mum).

(7) Verb + pronoun + the appellation of relatives. Examples are $q u$ ni $m a$ (fuck your mum), qu ni lao lao(fuck your granny-in-law), qu ni nai nai(fuck your granny), ri ta niang(fuck his mum), ri ni niang(fuck your mum), cao ni lao lao(fuck your granny-in-law), diao ni lao ma(fuck your mum), cao ni nai nai(fuck your granny), cao ni ma(fuck your mum), gun ni ma(to hell with your mum).

Structures (6) and (7) are almost the same, the difference is that the former has an auxiliary word $d e$ at the end, but the existence or absence of the auxiliary de determines whether the performative object of the verb, i.e., the recipient of the action, is clear or not. The object of the verb in structure (7) is what the appellation addresses whereas the object in structure (6) changes with the subject of the topic, for example:

17)操他妈的,电话怎么老打不通呢。

-Cao ta ma de, dian hua zen me lao da bu tong ni.

-Fuck his mum's, telephone why always cannot get through.

-Damn it, why can't I get through (the phone)?

18)操他妈的, 这玩意儿这么难学, 我再也不想学了。

-Cao ta ma de, zhe wan yi er zhe me nan xue, wo zai ye bu xiang xue le.

-Fuck his mum's, this thing so difficult learn, I no longer want learn.

-Fuck, it is so hard to learn, I don't want to learn it anymore.

The recipient of the performative verb cao (fuck) in the two sentences can be understood as telephone, English, mathematics, handcraft, computer programming etc., so the two sentences can be logically reproduced as

19)操他妈的电话,(你的电话)怎么老打不通呢。

-Cao ta ma de dian hua, (ni de dian hua) zen me lao da bu tong ni.

-Fuck his mum's phone, (your telephone) why always cannot get through.

-Damn the phone, why can't I get it through?

20)操他妈的英语(数学、手艺、编程、呼啦圈), 这玩意 儿这么难学,我再也不想学了。

-Cao ta ma de ying yu (shu xue, shou yi, bian cheng, hu la quan), zhe wan yi er zhe me nan xue, wo zai ye bu xiang xue le.

-Fuck his mum's English (mathematics, handcraft, programming, hu la hoop) this thing so difficult learn, I no longer want learn.

-Fuck English (mathematics, handcraft, programming, hu la hoop), it is so hard to learn, I do n' t want to learn it anymore.

Generally speaking, the pronouns in structures (6)(7) are the second person or the third person singular. Because of the emergence of the verbs, the insulting meaning behind the structure is the most obvious and the pragmatic effect is the strongest. It is interesting that the appellations of these two structures can be kinship appellations, such as qu ni nai nai (de) (to hell with your grandmother's), or non-relative appellations, and the appellations can be adjusted accordingly with the changes of the objects referred to in the topic, as in sentences 20 and 21. The appellations in the other structures above mentioned do not allow the appearance of non-relative appellations. For instance, (ta) ma de ((his) mother's) is allowed but (ta) lao ban de ((his) boss's) is not, ni lao lao de (your grandmother's) is allowed but ni lao ban de (your boss') is not. The former are abusive in illocutionary effect whereas the latter are not.

21)整天就是你老师你老师,去你的老师(或去你老师的), 不管你老师同意不同意,我们今天都要把这事先办了。 -Zheng tian jiu shi ni lao shi ni lao shi, qu ni de lao shi (qu ni lao shi de), bu guan ni lao shi tong yi bu tong yi, wo men jin tian dou yao ba zhe shi xian ban le.

-All day is your teacher your teacher, go your teacher, no matter your teacher agrees or not agrees, we today must this thing at first handle.

-All day you say "my teacher" again and again, fuck your teacher, whether he agrees or disagrees, we must deal with it today.

22)去你老板的,你以为没有他你就会饿死不成?

-Qu ni lao ban de, ni yi wei mei you ta ni jiu hui e si bu cheng?

-Go your boss', you think without him you will die from hunger?

-To hell with your boss, do you think that you will die from hunger without his offer?

In addition, the verbs in this kind of structures are theoretically non-restrictive. Any verb can be acceptable, such as 去 $q u$ (go), 滚 gun (fuck off), 令 diao (fuck), 帛 diao (fuck), 操 cao (fuck), 看 kan (watch), 读 $d u$ (read), 唱 chang (sing), 写 xie (write) etc.. The verbs used in these structures are often those verbs with derogatory and scolding meanings. The verbs 去 $q u$ (go), 滚 gun (fuck off), 肉 diao (fuck), 帛 diao (fuck), 操 cao (fuck) are synonymous, but in 
writing the verb 操 $c a o$ is usually used to replace the other synonyms related to sexual organs or sexual behavior. What verb is chosen and used in this structure is flexibly adapted to the requirements of the context, as in the following:

23)滚你妈的,别在这里瞎羒。

-Gun ni ma de, bie zai zhe li xia bai.

-Roll your mother's, do not here talk nonsense.

-Fuck off, stop talking nonsense.

24)屌他妈的,把老子当成什么人了。

-Diao ta ma de, ba lao zi dang cheng shen me ren le.

-Cock his mother's, take me as what person.

-Fuck up, what do you think I am?

25)看看看,看你妈的,有什么好看的。

-Kan kan kan, kan ni ma de, you shen me hao kan de.

-Look look look, look your mother's, have what worth looking.

-Always say "look", fuck, what the hell is worth looking?

26)读你妈的,这么晚了还大声读, 别人要不要睡觉?

-Du ni ma de, zhe me wan le hai da sheng du, bie ren yao bu yao shui jiao?

-Read your mother's, so late still loud read, others want or not sleep?

-To hell with your reading, you keep reading so loud and so late. How can others sleep?

27)工作你妈的,你除了工作,心里还有这个家吗?

-Gong zuo ni ma de, ni chu le gong zuo, xin li hai you zhe ge jia ma?

-Work your mother's, you except work, in mind still there is a family?

-Damn your work, except for your work, do you still care about the family?

(8) First person pronoun + verb. Examples are wo kao (I fuck), wo cao (I fuck), wo qu (I fuck). This structure is characterized by the fact that it always appears with the first person singular at the initial position. In fact, it can be regarded as the simplification of a complete sentence wo cao(kao, qu) ni ma de X (I fuck your mother's X), in which wo cao is a more traditional Chinese scolding word, whereas wo kao is a new Chinese scolding word, widely spread online in recent years.

In addition to the eight main types of national abuse listed above, there are many other local variations, such as 娘希匹 (niang xi pi, fuck mother), 狗日的(gou ri de, son of a bitch), 狗屌的 (gou diao de, dick), 球( qiu, dick), 屌(diao, dick), 操 蛋(cao dan, fuck egg), (死)八婆(si ba po, (dead) woman), 臭三八(chou san ba, stinky woman), 屁精 ( pi jing, fart essence), 马屁精( ma pi jing, fart essence), 杂种( $z a$ zhong, bastard), 混蛋(hun dan, bastard), 浑蛋(hun dan, bastard), 操蛋(cao dan, fuck), 扯淡 (che dan, bullshit), 王八操的 (wang ba cao de, turtle fuck), 狗娘养的(gou niang yang de, son of a bitch), 老不死的(lao bu shi de, damn you), 丘八 (qiu ba, old soldier), 老棺材(lao guan cai, coffin), 老东西 (lao dong xi, old thing), 狗东西(gou dong xi, dog), 土鳖( $t u$ bie, turtle), 鳖头(bie tou, turtle head), 该死的 (gai si de, damn) [4, 17, 18],. These variants often appear in local dialects, their structure is relatively mixed, and they do not belong to the derivative structure of " $X+m a$ ", which are not within the scope of the discussion in this paper. The above-mentioned eight types of structures are summarized in the table below:

Table 1. The construction of Chinese-specific abuse X ma de and its variants.

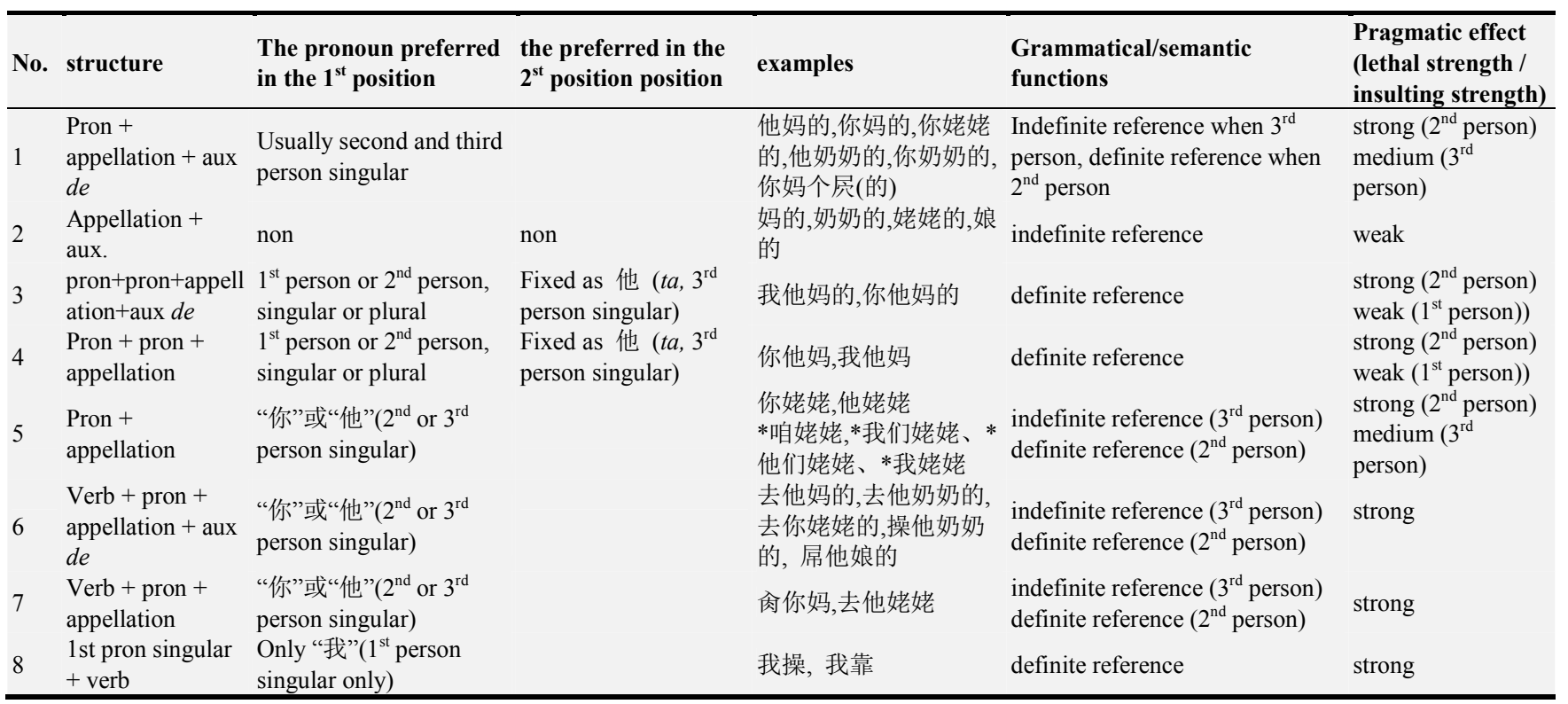

There are significant differences in the intensity of these eight forms of national abuse, the most lethal among them is "verb $+2^{\text {nd }}$ person pronoun + relatives appellations + auxiliary $d e^{\prime \prime}$, such as 操你妈的(fuck your mother)、屌你奶 奶的(fuck your granny). This kind of national abuses has the most lethal effect because they are the most insulting (marked by the appearance of sexually aggressive verbs) and the most direct (marked by the appearance of pronouns). The 
weakest is the structure of "kinship appellation + auxiliary $d e^{\prime}$, such as 妈妈的(mother's), 奶奶的 (grandmother's). This kind of national abuse has no possessive pronoun as modifier, the kinship appellation words in it only have universal meaning but no clear reference, therefore, they have no obvious insult. If we only take pronouns as the reference point, the most lethal is the structure with the $2^{\text {nd }}$ person pronoun (e.g. 你妈的 your mother's、你他妈的 you his mother's), the $2^{\text {nd }}$ most lethal is the structure with the $3^{\text {rd }}$ person (e.g. 他妈的 his mother's), and the $3^{\text {rd }}$ most lethal is the structure with the $1^{\text {st }}$ person (e.g. 我他妈的 I his mother's), the weakest is the no-person structure (e.g. 妈的 mother's).

The above mentioned essay by Li Ming Jiang Nan lists eight kinds of national abuse, which discusses it in a playful tone. The classification of the national abuse in it is of course not one in the strict academic sense. The above analysis shows that the national abuse can be classified in terms of its content, object of reference, degree of clarity, scope of use and so on. As far as its content is concerned, it is found from the observation of the corpus that most national scolding words are often related to sex (including sexual behavior, sexual organs, sexual ability, sexual products and other aspects related to sex). The sex-related scolding object is often female, and the most often scolded female person is the "X's mother ". Why do women, especially "mothers" and mothers' mothers (i.e. maternal or paternal grandmothers) rather than men, become victims of national abuse? This may be related to matrilineal clan society and the laws of natural reproduction. There is a saying that, although patriarchy enjoys absolute authority or even supreme status in ancient orthodoxies, mother's status is beyond father in people's mind. In a sense, the father is the symbol of right, order and ideal while the mother is the symbol of affinity, and the worship and attachment to motherhood is greater than that of the father. Therefore, scolding mothers is undoubtedly a blow to people's deep feelings of vulnerability, replacing the physical confrontation of primitive human or animals. In fact, scolding mothers is a kind of high-level provocation and challenge after human body expression is transformed into language expression [14]. As for how the national scolding is formed? The causal relationship in this respect needs to be further explored. Interestingly, this type of abuse is mostly used by men, but not limited to men. We did a questionnaire survey and found that in daily life, there are quite a few women using national abuse, the difference is: women rarely use it in public and mostly among their best friends. The use of national abuse by men is not so much limited by the occasion.

Although national abuse is related to women, in fact, in most cases there is no very precise target. As far as the object of reference is concerned, national abuse can be divided into two types, i.e., general and specific, according to their scope of reference. The general type is mostly initiated by the third person singular, such as 他妈的 (his mother's), or not guided by any pronoun, such as 奶奶的 (grandmother's), while the specific type is mostly initiated by the second person pronoun singular, such as 你妈的(your mother's) and 你奶奶的(your grandmother's). National abuse can also be divided into self-scolding type and other-scolding types according to their specific objectives of the dialogue. The former is initiated by first person singular, expressing self-reproach, for example, “我他妈的, 唉, 我真不该投那 笔钱进去”(I fucking, alas, I really shouldn't put that money in." The latter is initiated by second person singular, expressing criticism or aggression, for example, “你他妈的, 你怎么说话呢。”(You fucking, what the fuck do you talk?).

In terms of their straightforward degree and pragmatic effect, the above eight types of national abuse can be roughly summed up as straightforward and euphemistic (or vulgar and elegant) types. The main difference between them is in their syntactic structures. The straightforward or vulgar abuse is added by some nouns or verbs about sex or sexual behavior, such as 你妈(个)屄(your mother's pussy), 操你姥姥(fuck your grandmother). The euphemistic or elegant abuse will not be added by such words, such as 奶奶的(grandmother's), 他 妈的(his mother's).

\section{The Function and Meaning of National Abuse}

Language and characters are created by human beings, but in the face of the magical effect of language and characters, people worship them as something holy. They use language to bless, curse, convey feelings, give orders, etc. [1, 9, 12]. They choose auspicious words to form their own names, and the names of city, objects and shops. They even believe that a person's name is associated with personal misfortune, so the name should be tabooed. In ancient China, the name of the emperor, officers, ancestors and the elders could not be used as address term, which is regarded as being polite by later generations but as a way of personal protection by people in ancient times. In modern spoken Chinese, there are some words originated from taboo; not long ago, many industries had their own taboo words. In short, language has a certain function or is given a certain function, any language is used for a certain purpose, the same is true of national abuse [cf. 5, 8]. We can analyze the function of national scolding from two aspects, namely its meta-language function and its social pragmatic function.

The use of language serves for conducting a pragmatic behavior or realizing a pragmatic purpose. The basic purpose of national abuse is to carry out a certain speech act, and to perform a speech act is invariably expected to achieve a certain perlocutionary effect $[1,9,12]$. The above mentioned essay by Li Ming Jiang Nan classifies national abuse from the perspective of the pragmatic effect and perlocution when a speech act is performed, which includes such negative social pragmatic functions as catharsis, anger, protest, complaint, etc. In addition, we also find that national scolding can also express positive social functions such as pleasure, excitement, happiness, satisfaction, appreciation and so on [cf. 2, 8, 12]. Compare (27-28) and (29-32) 
28)A：他说你是熊包。B: 他妈的。

-A: ta shuo ni shi xiong bao. B: ta ma de.

-A: He said you are a bear. B: His mother's.

-A: He said you are good-for-nothing. B: Fuck.

29)A: 我把你的面都吃完了。B: 他妈的,那我吃什么。

-A: wo ba ni de mian dou chi wan le. B: ta ma de, na wo chi shen me.

-A: I take your noodle all eat up. B: His mother's, then I eat what.

-A: I ate up all your noodle. B: Oh my God, what am I gonna eat?

30)奶奶的,这回我终于拿下了冠军。

-Nai nai de, zhe hui wo zhong yu na xia le guan jun.

-Granny's, this time I finally won the championship.

-Gosh, I got the championship at last this time.

31)(喝完饮料后)他娘的, 真爽!

- (after drinking)ta niang de, zhen shuang!

- his mother's, really cool!

-fucking, it's really cool!

32)A: 我把这个纠缠我们多年的难题解决了。

B: 他妈的,你真行。

-A: wo ba zhe ge jiu chan wo men duo nian de nan ti jie jue le.

-B: ta ma de, ni zhen xing.

-A: I let this haunting us many years difficult problem solved.

-B: His mother's, you really great.

-A: I solved this difficult problem that has haunted us for many years.

-B: Fuck, you're smart.

33)A：我终于把她追到手了。

B: 他妈的,好小子。

-A: wo zhong yu ba ta zhui dao shou le.

-B: ta ma de, hao xiao zi.

-A: I finally caught her in my hand.

-B: his mother's, good boy.

-A: I finally got her.

-B: Fuck, attaboy.

After many years of evolution, Chinese national curse has now not only become a phrase used to perform the pragmatic function of swearing but also developed a grammatical cognitive function, that is, from a grammatical cognitive point of view, it sometimes may act as a grammatical modifier and play a role of semantic reinforcement, as in "我 他妈的那个爽呀! (I am fucking comfortable!)" The"他妈的 (fucking) "and "那个(that)"in this sentence do not target at anything nor have a clear meaning. Instead, they cooperate to serve as semantic and mood intensifier, semantically similar to "very or quite". Without these reinforcement modifiers, this sentence still works and is still semantically complete and clear. However, the sentence without these intensifiers will become much weaker in the intensity of mood and meaning expression. Particularly in emotional expression, the function of such national scolding words is irreplaceable by other general adverbs. It is interesting to note that the national curse with this reinforcement function can also be preceded by a modifying adverb such as "真(really)", and the word order of 他妈的 (his mother's) and 真 (really)are totally flexible, i. e., 他妈的 before 真, or 真 before 他妈的, as in

\section{4)我他妈的真倒霉,怎么总是碰到这样的事。}

-Wo ta ma de zhen dao mei, zen me zong shi peng dao zhe yang de shi.

-I'm his mother's really unlucky, why always come across such thing.

-I'm so fucking unlucky, how come I always come across such affairs.

35)我操他奶奶的真晦气, 又和这个狗娘养的畜生坐到一 个办公室了。

-Wo cao ta nai nai de zhen hui qi, you he zhe ge gou niang yang de chu sheng zuo dao yi ge ban gong shi le.

-I fucking his granny's really unlucky, again with this bitch's creature sit in the same office.

-I was fucking so unlucky that I sat again in the same office with this son of a bitch.

Chinese national scolding words or phrases are often regarded as taboo because their meanings are more or less offensive and impolite. The above analysis shows these words do not have a clear lexical meaning, but have a significant pragmatic meaning and a certain grammatical cognitive meaning. From the perspective of their social-pragmatic function, what they express is nothing but a certain kind of strong emotion. As for what type of strong emotions are expressed, positive or negative? praising or derogatory? intimate or exclusive? It can't be clarified except in a certain communication environment. In addition to being influenced by the communicative environment, their significance may also be influenced by the lexical collocation structure in the discourse. When they are used together with other words with obvious meaning tendency, their pragmatic meanings become apparent [cf. 8, 12, 11].

Based on the above analysis, we can see that what the national scolding words express is not necessarily a strong negative emotion, instead, their meaning is wandering between two extremes: strong and weak. Their specific intensity depends on the specific communicative environment and the structural environment of sentence collocation. The pragmatic principles proposed by the Relevance Theorists [10, 16] or Linguistic Adaptation Theorists [12] may help make inference and arrive at the right decision of its pragmatic force as well as its pragmatic strength in a context.

\section{Conclusion}

This paper has presented an analysis of the forms and types, language function, and meaning interpretation of the most common Chinese national scolding Ta Ma De and its variants. It is found that this language phenomenon has both social-pragmatic as well as grammatical-cognitive functions. Its pragmatic forces or functions can be both negative and positive, and can sometimes achieve unexpected unique effects in the expression of emotions, attitudes and emotions. Thus, it is held that, as a common linguistic phenomenon, its 
existence has its own rationality and pragmatic motivation. In daily communication, although we do not encourage the use of it, it should be treated appropriately and not be fully banned because of its vulgarity and inelegance. The words of national curse ta ma de and its variants, their usage should be included and interpreted in dictionaries, and analysis and attention should be given to it in grammar or lexical books. So far, there are few studies on Chinese scolding words, their composition rules, causes and comparative analysis and translation of Chinese and foreign scolding words are all worth our further discussion [cf. 5, 11, 15, 17].

\section{Funding}

This paper is part of the research projects "A Chinese-English Parallel-Corpus-Based Study of the Factors Influencing Irony Cognition and Understanding and their Working Mechanism" (17 YJA740005), "A Corpus-based Study of the Influencing Factors of Verbal Irony Understanding" (GD16CWW01), "A Corpus-based Study of the Pragmatic Mechanism of the Influencing Factors in Irony Understanding" (19BYY004), "An exploration of the network talk show Disclosing Secrets from the perspective of Hermeneutics" (CSY-2021-YA-05), funded respectively by the Ministry of Education, Guangdong Province, National Social Science Fund PRC, Guangdong University of Foreign Studies.

\section{References}

[1] Austin, J. L. How to do Things with Words: The William James Lectures delivered at Harvard University in 1955 [M]. Ed. J. O. Urmson. Oxford: Clarendon, 1962.

[2] Huang, Hui. On the refinement of Chinese abuse and its variants, Journal of Chinese. 2016, (04): 53-54.

[3] Jiang, Jiebao. On the motive and role of swearing [J]. Journal of Anqing Normal College (Social Sciences), 1999 (1).

[4] Jiang, Jiebao. On the construction and classification of swearing $[\mathrm{J}]$. Journal of Anqing Normal College (Social Sciences), 2000 (1).
[5] Lu, Licheng \& Aifen Li. Swearword Translation in Steve Jobs: A Communicative/Semantic Perspective [J]. English Language and Literature Studies, 2020 (1).

[6] Lu Xun. On "Ta Ma de (fucking)!" [J]. Yu Si, 1925 (37).

[7] Lu Xun. The Complete Works of Lu Xun [M]. People's Literature Press, 1982: 232.

[8] Niu, Penghua. A Study on the semantic connotation of -class words (words about vaginal orifice) in modern Chinese society from the perspective of social linguistics. Chinese character culture. 2021 (01): 143-145.

[9] Searle, John. Expression and Meaning: Studies in the Theory of Speech Acts [M]. Cambridge: Cambridge University Press, 1979.

[10] Sperber, D. \& D. Wilson. Relevance: Communication and Cognition [M]. Oxford: Blackwell. Second edition, 1995.

[11] Valdeón, Roberto A. Swearing and the vulgarization hypothesis in Spanish audiovisual translation [J]. Journal of Pragmatics., 2020 (Vol. 155): 261-272.

[12] Verschueren, Jef. Understanding Pragmatics [M]. London and New York: Arnold. 1999.

[13] Wang, Qingxia. Some objections against Lu Xun's essay titled On "ta ma de" (fucking)! Lu Xun Research Monthly. 2017, (12): 20-23.

[14] Yao Chunrong. Research on Chinese abuse [D], Master's Degree Dissertation of Jinan University, 2009.

[15] Zeng, Yantao \& Yuemei Liu. Relevance strategy in reading and reading instruction, Humanities and Social Science, 2021. 4.

[16] You, Hui ying \& Zhi xiang Sun. On the Chinese Translation of Swearwords in English Films Under the Polysystem [J]. Journal of Literature and Art Studies. 2021 (2).

[17] Zhou Hailin. A contrast of Chinese and Western abuse [J], Journal of Hunan Industrial Vocational and Technical College (Social Sciences), 2010. 1.

[18] Zhang, Keying. Some Thoughts over Lu Xun's essay titled On "ta ma de" (fucking)! [J], Chinese Character Culture, 2020 (2): 104-105. 